\title{
Ezhou Carved Paper Cutting Research
}

\author{
Peng LI \\ Shanghai University of Engineering Science, Art and Design College
}

\begin{abstract}
This paper illustrates the regional characteristics of Ezhou carved paper cutting, analyzing the content of Ezhou carved paper cutting, technique and form, recorded and inheritance of folk culture vividly, it has realistic and historical social influence for the development of Ezhou cultural and creative industries, promote the competitiveness of the local economy.
\end{abstract}

KEYWORD: Carved paper cutting; Regional characteristics; Text into the figure; Folk inheritance

Ezhou is a city of profound history and culture, it located in the southeast of Hubei province. From the view of historical geography, it is an old saying as "head of $\mathrm{Wu}$, Tail of Chu". The blending and impact of $\mathrm{Wu}$ and $\mathrm{Chu}$ Culture formed distinctive artistic features here .which form an unique artistic style of Ezhou carved paper cutting, playing an important role in the history of Chinese folk paper cutting. On June 7th, 2008, Ezhou carved paper cutting has been announced as the national first batch of intangible cultural heritages published by the state council. On August 19, 2010, it included in the UNESCO intangible cultural heritage list. The Chinese paper cutting art has distinctive difference, "The North cut, the south carve". Because it is widely used by scissors to cut paper in North, while in south the mainly tool is scorper, the difference is obvious. Ezhou carved paper cutting has formed a unique regional characteristics.

\section{THE REGIONAL CHARACTERISTICS OF EZHOU CARVED PAPER CUTTING}

In ancient times, the Ezhou is possession of Chu. Therefore, the Ezhou Culture has great richness and diversity, not only with distinctive and unique morphological characteristics of $\mathrm{Chu}$ culture, but also due to the influence of Three Kingdom culture, presenting the impact and blend of $\mathrm{Chu}$ and $\mathrm{Wu}$ culture. Chu culture is brilliant, beautiful, mysterious exotic and special, and $\mathrm{Wu}$ culture is delicately beautiful, which add brilliance and gorgeousness to each other, constitute the uniqueness of Ezhou regional culture. The domestic theory study on Ezhou carved paper cutting attaches great importance on the regional culture style. If not studying and researching the Ezhou carved paper cutting from the view of cultural characteristics, it is difficult to be aware of its cultural value. Ezhou is a place where a variety of cultural convergence, it is the birthplace of bronze culture, and Chu culture, $\mathrm{Wu}$ cultural, religious culture and their integration. Not only it absorbs and presents the characteristic of different local culture, but also make Ezhou carved paper cutting more compatiable, open, with intensive artistic features.

About the materials selection, folk paper cutting perfer to using eye-catching red paper. Ezhou folk pattern paper cutting mainly choose thin white or yellow rice paper; for the consumer group selection, folk paper cutting are widely made for family and householder. While Ezhou carved paper cutting regard folk embroidery artists as leader, from the observation of the design of the production process, with relatively freedom of folk paper-cut creation, wide range of subject choice, producing by primarily using scissors and knife ,Forming one piece of work at one time. The subject is subject to the functional Ezhou carved paper cutting, it has certain directivity. During producing process, fix the stack of paper into on top of the wax plate, carefully cut with a special knife to complete works. In the view of the work frame system, the principal folk paper-cut is square, round, fan, etc., and ezhou folk paper cutting frame format must be consistent with the shape of dress, and presents a suitable form.

According to the requirement of embroidery, there should leave some mouldings and stitch marks in the pattern, to prepare for embroiderer used. It is these marks, which make artistic images of the surface shape as the main body in pattern rich in 
various of change. It innovate a paper-cut ruled cone pressure technique, creating a unique paper-cut art style different from others. The main Ezhou paper cutting and engraving tools and materials include in rice paper, wax, scissors, tweezers, awl and carved box, carved drum etc. Through "incised" "carved" and "incised and carved combination", it can cut and carve more than 10 pieces of the same works. Their patterns spread around the country, throughout both side of Yangzi River. The fine soul art of "it won't cut off and fall down during the hundred and thousand times of paper cutting "to affect millions of householders, due to the well proportioned structure works, using combination both cutting and engraving skills, in delicate, smooth and vivid style, the works have great value for collection and practical art. The Ezhou Unique paper cutting and engraving technique is amazing miracle.

\section{THE CONTENT OF EZHOU CARVED PAPER CUTTING, TECHNIQUE AND FORM}

The artistic content of Ezhou carved paper cutting.

The content is divided into six parts: First is auspicious blessings; Second is to reflect historical imprint; Third is love and marriage; Fourth is family multiply; Fifth is God bless and drive away evil spirits. Sixth is to pray for good natural weather. As a direct descendant descendant of the original culture, through the collective unconscious or conscious collective representation heritage, paper cutting reflects the creative idea directly, to focus on the idea "pattern with significance, significance is auspicious.

\subsection{The subject of animal graphics}

Ezhou carved animal graphics processing paperwork adopts naturalistic realist approach, to grasp the major features of animal images, daring to minor details and make the images clear at first glance, with distinctive features of plain and exaggrated. Ezhou carved papercutting artists are mostly rural women, they perfer to creat animal graphics in accordance with folk customs and personal aesthetic preferences, such as feeding chickens, pigs, sheep, cattle, coming back to her parents' home, and carrying a baby etc.. Among them, the most representative of infant apparel "Saliva surround by Tiger-shaped" paper cutting. It is well known that infant of five or six months, generally increasing salivary gland secretion, while the children swallowing function is not perfect, and the baby has a small shallow mouth, resulting in continuous saliva flowing out, dirt over his chest. In order to keep infant clothing healthy and beautiful, intelligent artists have fantastic idea, to carve charming naivety, colorful and lovely auspicious animals graphic symbols instead of hideous tiger-shaped, accompanying "little angels" day and night. For protecting children from evil spirits and give more blessing on their healthy, to expect the children grow up easily and happily, without any sick or accident, it is a kind eager of better life. It contains profound folk implications. During the 2008 Beijing Olympic Games, Beijing Guomao subway station hang four pieces of paper-cut patterns, one of which is the Ezhou paper cutting work "Saliva surround by Tigershaped". (Figure 1)

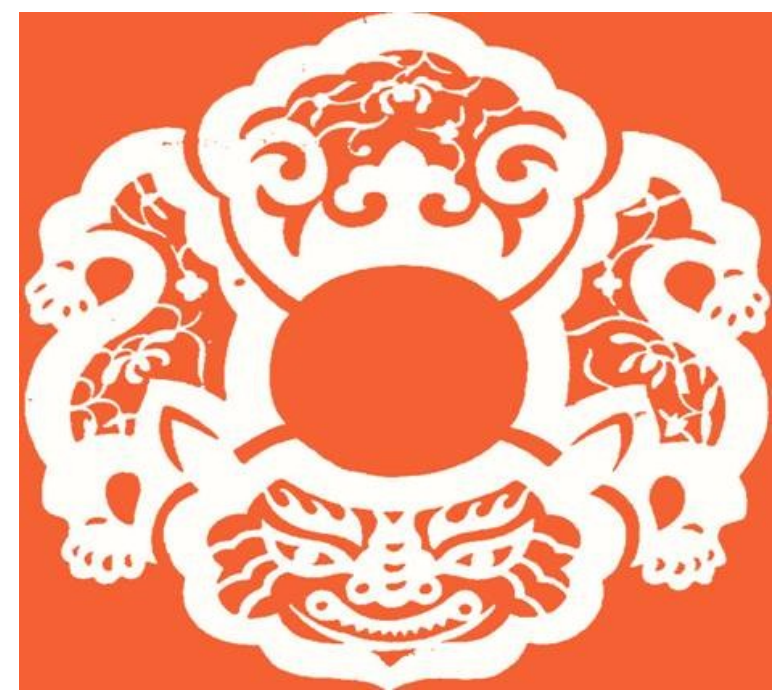

Figure 1. Saliva surround by Tiger-shaped

\subsection{The subject of plant graphics}

Beside animal graphics, there are auspicious plant graphics, such as plum, orchid, bamboo, chrysanthemum and fruits and vegetables, the subjects come from life, such as masculine "fish", feminine "flower" in "ribbon flower". People perfection psychology reflects on the plants graphic symbol, in the form of in pairs with harmonious symmetry. Folk artists consider only one alone as a taboo, pay more attention on the perfect symmetry, even number of plant graphical symbols. In public opinion, symmetrical and even number breed peace, perfection and good luck. Folk arts and crafts often in pairs, whether it is character of people, animals or plants. For example, no matter who is chosen to serve as, the goalkeepers always appear in pairs on either side, as well as the "double Dragon", "double Phoenixes", "couples of fish ", "pairs of bird" in folk art .

\subsection{The subject of text graphics}

As the representative of the southern paper cutting, Ezhou carved paper cutting has long history, and "add text into the pattern" reflects the most common and simple pursuit of artistic ideas and aesthetics by Ezhou paper cutting artists, which also contains the most basic and profound national conception and culture. It is good at using "poetry", "couplet", "four 
\& eight sentences" to shape traditional artistic characterizations, and make them extend and develop in the paper cutting art. On the other hand, people worship the text. Although the people living on the bottom of society are not well educated, even illiterate, they are advocating culture, the worship of text, eager to scientific knowledge. In these text, there are lots of folk characters, wrong characters and self-created characters, as the result of limit education level of creators, but today it seems plain, lovely, abundant charming.

\section{THE FORM OF EZHOU CARVED PAPER CUTTING}

"Adding text into the pattern" is the major features of Ezhou carved paper cutting. There are full use of text strap pattern, and other pattern forms combinating text with visual symbols. The text as a visual language symbols in the design, its content, size, shape, orientation, location etc., are consciously subordinate to the whole visual language expression art. The use of text content have been hammering out. This paper-cutting work "after graduation, studying abroad better" reflects that, after reforming and opening-up people have wider international vision, eager to accept the world-class education, respect knowledge, respect talent. They sent their children to study abroad after graduation. The demands people yearning for better future convert from materials to spirits.

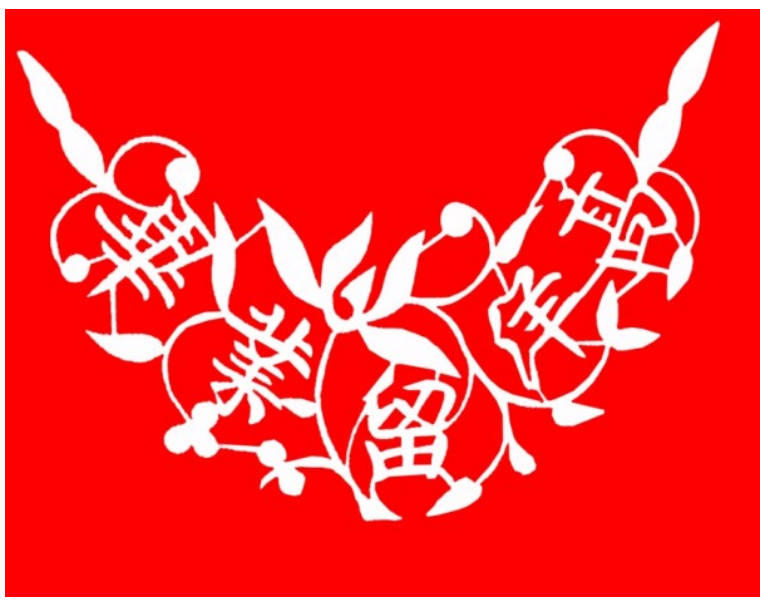

Figure 2. after graduation, studying abroad better"

Ezhou carved paper cutting flexibly using "crescent pattern", "sawtooth lines" make the works with a sense of carving knife, such as Ezhou Fankou folk paper cutting work "Shoe-flower--magpie \& persimmon figure ". In the producing process, author staggered use "crescent pattern ", "sawtooth lines" to make the works profound, accurate, clear structure and rich of change. In this work, the authors use the change of sawtooth pattern, its length, density, firm, soft ,blunt, sharp , combined with the features of the magpies feather, using the natural movement between paper and a knife to show its features, performance texture, sense and structure. When design the character of persimmon, the author incise "crescent pattern" to destroy large areas of persimmon shape, using the size, length and width of "crescent pattern" to depict the structural character, shape and growth direction accurately.

Ezhou carved paper cutting utilizes the internal link between charater and content, mixing with different technique, with the form of "accumulated by layer and layer" "different object in each scene", adopting exaggerated deformation on the shape, using symmetry, uniformity, balance, continuous to make the pattern design in structural beauty. To design and arrange the birds on the sky, fishes under the water and buildings on the floor to appear in one screen, this horizontal composition creation form their own unique decoration style.

Ezhou carved paper cutting technique is in colorful and various style, including in burning, color matching, color contrast, dyeing, printing, coloring techniques, using bold and flexible technique, simple and bright colors, to show simple in the complex work, or reflect complex in the simple work. Using subtle color contrast, to find its coordination and harmonization in the contrast. This not only bring the festival atmosphere of life, but also rich artistic aesthetic taste. At the same time, it is positive to advocate justice, promote social harmony and enhance regional cultural taste.

III. he folk inheritance and development of the Ezhou carved paper cutting

\subsection{The living fossil of traditional art}

The inheritance of the Ezhou carved paper cutting

As an important part of Chinese intangible cultural heritage, Ezhou carved paper cutting is a brand of regional culture, included in the first batch of national intangible cultural heritage list. It has become a huge intangible assets, with greater appreciation room and economic development value.

Ezhou carved paper cutting embodied the simplicity of the original ecological characteristics, with obvious regional cultural characteristics. The original ecology is the source of original art of life, it shouldn't be discarded. Therefore, the direction to study the Ezhou carved paper cutting from the perspection of ecology is immutable.

With the ecological conception to know Ezhou carved paper cutting art, make an analysis and discussion on the artistic value of Ezhou carved paper cutting in the cultural and historical level. From the theoretical research of the form of Ezhou carved paper cutting, not only aesthetic form, performance skills, understanding rises to the height of the rational, but also discusses the Ezhou carved paper cutting romantic expression and its cultural 
connotation from the art aesthetic. The most important thing is how to make the Ezhou carved paper cutting become the cultural and creative industry, put forward to the reform of the superior cultural industry and measures.

\subsection{The development of Ezhou carved paper cutting}

Ezhou carved paper cutting is very novel performance, speaking highly of socialist modernization drive, accelerating regional economic development, such as "bream jumping over dragon door"(figure 3) is the "carp" is replaced by "bream", "bream" that is "Wuchang fish ". This figure is different from traditional pattern, in which the fish leaping high, only see two fishes with several wave lines, make people get visual association immediately, it seems water flowing, fish are swimming also. The characters and objects are in natural shape and distinctive features, make audience realize it is true and kind, full of vivid artistic charm.

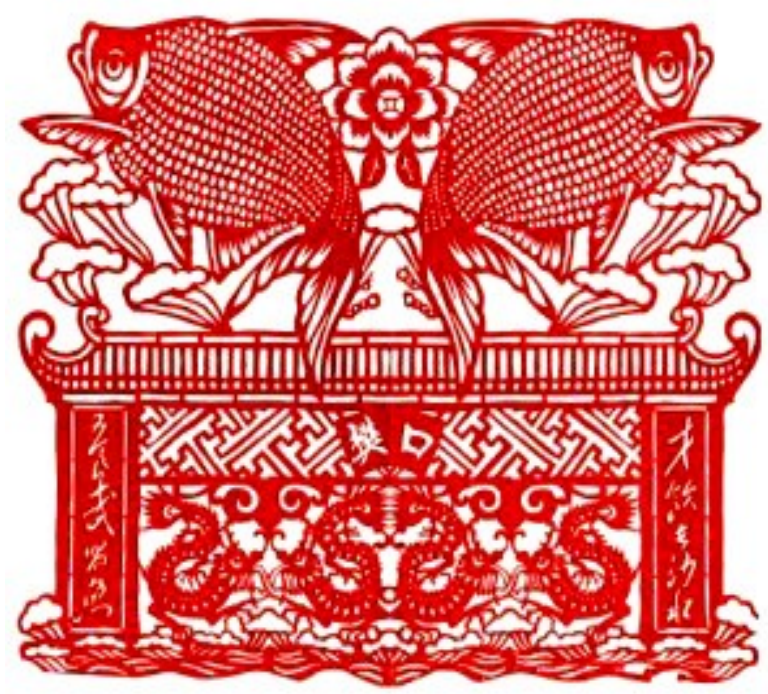

Figure 3. bream jumping over dragon door

\section{CONCLUSION}

With the exploration of national intangible cultural heritage and its further organization work, he artistic value Ezhou carved paper cutting appeal to more and more people's attention. On one hand, o interpret semantic expression on the Ezhou paper cutting auspicious symbols, on the other hand, hrough interdisciplinary collaboration, to put forward the development measures and make Ezhou carved paper cutting change from the traditional papercutting art advantages into economic advantages, playing a role of the media to make cultural and creative industries, to promote the development of Ezhou tourism economy. In turn, with the development of tourism, it can bring more boost of Ezhou carved paper cutting, even make it become famous cultural brand in Ezhou as well as around the country.

\section{REFERENCES}

[1] South-Central People's literature and Art Press, 1953.06. Hubei Province artistic studio: Hubei folk carved paper cutting art.

[2] Grand stage, 2012.12. Chen Qirui: Research of Ezhou carved paper cutting ausicous symbols.

[3] Journal of Ezhou University, 2006.05.Li Shisheng: The artistic value of Ezhou folk carved paper-cutting.

[4] Chinese folk carved paper-cutting study, 2007.08.Hou Yanan. The analysis of text into pattern in Ezhou carved paper cutting.

[5] Art Introduction, 2008.09.He Shiyan: Introduction to Ezhou folk carved paper-cutting. 